\title{
KRAS rs61764370 is associated with HER2- overexpressed and poorly-differentiated breast cancer in hormone replacement therapy users: a case control study
}

\author{
Jasmina-Ziva Cerne ${ }^{1}$, Vida Stegel ${ }^{2}$, Ksenija Gersak $^{1}$ and Srdjan Novakovic ${ }^{2^{*}}$
}

\begin{abstract}
Background: A single nucleotide polymorphism located in the 3'-untranslated region of the KRAS oncogene (KRAS variant; rs61764370) disrupts a let-7 miRNA binding and was recently reported to act as a genetic marker for increased risk of developing human cancers. We aimed to investigate an association of the KRAS variant with sporadic and familial breast cancer and breast tumor characteristics.

Methods: Genotyping was accomplished in 530 sporadic postmenopausal breast cancer cases, 165 familial breast cancer cases (including $N=29$, who test positive for BRCA1/2 mutations) and 270 postmenopausal control women using the flurogenic 5 ' nuclease assay. Information on hormone replacement therapy (HRT) use and tumor characteristics in sporadic breast cancer cases was ascertained from a postal questionnaire and pathology reports, respectively. Associations between the KRAS genotype and breast cancer or breast tumor characteristics were assessed using chi-square test and logistic regression models.
\end{abstract}

Results: No evidence of association was observed between the KRAS variant and risk of sporadic and familial breast cancer - either among BRCA carriers or non-BRCA carriers. The KRAS variant was statistically significantly more often associated with human epidermal growth factor receptor 2 (HER2) - positive tumors and tumors of higher histopathologic grade. However, both associations were detected only in HRT users.

Conclusion: Our data do not support the hypothesis that the KRAS variant rs61764370 is implicated in the aetiology of sporadic or of familial breast cancer. In postmenopausal women using HRT, the KRAS variant might lead to HER2 overexpressed and poorly-differentiated breast tumors, both indicators of a worse prognosis.

Keywords: KRAS rs61764370, Breast cancer, Tumor characteristics, Hormone replacement therapy

\section{Background}

MicroRNAs (miRNAs) are a class of small non-coding RNAs that function as negative gene regulators. Depending on the degree of complementarity between the miRNA and its target mRNA, miRNAs post-transcriptionally regulate target gene expression by either inhibiting mRNA translation or inducing mRNA degradation [1]. Recent evidence has shown that impaired miRNA expression or single nucleotide polymorphisms

\footnotetext{
*Correspondence: snovakovic@onko-i.si

2Department of Molecular Diagnostics, Institute of Oncology Ljubljana,

Zaloska 2, Ljubljana 1000, Slovenia

Full list of author information is available at the end of the article
}

(SNPs) that reside on miRNAs and/or miRNA-binding sites correlate with various human cancers [2]. Depending on target mRNAs, miRNAs can function as tumor suppressors or oncogenes [3].

The let-7 family of miRNAs plays an important role in tumorigenesis by regulating the expression of multiple oncogenes, including KRAS [4]. A germline SNP rs61764370 is located in the 3'-untranslated region of the KRAS oncogene and is referred to as the KRAS variant. The KRAS variant was demonstrated to be functional by disrupting a let-7 miRNA-binding site, and therefore leading to increased KRAS levels in vitro [5]. The same group also identified the KRAS variant to be

\section{() Biomed Central}


associated with 2.3-fold increased risk for non-small-cell lung cancer (NSCLC) among moderate smokers [5]. By other report, tumors containing the KRAS variant allele had lower let-7 levels, which has been associated with shortened postoperative survival in NSCLC [6]. The presence of the KRAS variant was likewise associated with poor prognosis in head and neck squamous cell carcinoma as well as with the 2.5-fold increased risk of developing epithelial ovarian cancer (EOC) $[7,8]$. The variant allele was identified in $25 \%$ of non-selected EOC cases and in $61 \%$ of EOC patients from hereditary breast and ovarian cancer (HBOC) families previously considered uninformative for gene mutations [8]. However, data from a subsequent meta-analysis excluded the possibility of an association between the KRAS variant and a clinically significant risk of unselected, serous, familial EOC, or EOC among women carrying deleterious mutations in BRCA1 [9].

Since the KRAS variant was reported to be enriched in ovarian cancer patients from HBOC families, the study by Hollestelle and colleagues further investigated the frequency of the $K R A S$ variant in breast cancer families [10]. As compared to the presence of the variant allele among controls (17.3\%), the increased frequency of the $K R A S$ variant was confirmed in breast cancer cases from BRCA1 families (23.5\%), but not among breast cancer cases from BRCA2 (13.5\%) or non-BRCA1/2 families (15.8\%) [10]. Another study found the KRAS variant to act as a genetic marker for increased risk of developing triple negative breast cancer in premenopausal women (OR 2.31, 95\% CI 1.26-4.22) [11].

On the basis of the current evidence, the purpose of our study was to investigate the association of the KRAS variant with sporadic and familial breast cancer risk among Slovenian women. Furthermore, we aimed to investigate the association of the $K R A S$ variant with breast tumor characteristics among Slovenian postmenopausal sporadic breast cancer cases stratified by hormone replacement therapy (HRT) use.

\section{Patients and methods}

\section{Study population}

Participants were those of our previous breast cancer case-control study [12]. In brief, we enrolled postmenopausal women, who were 50-69 years old and of Caucasian ethnic origin. Cases diagnosed with invasive primary breast cancer were enrolled from the Institute of Oncology Ljubljana. Control women were randomly recruited from the outpatient clinic records of the Department of Obstetrics and Gynecology, University Medical Centre Ljubljana during their routine gynecologic exams. Response rates and exclusion criteria for the participants have been published previously [12].
The present analysis includes also a cohort of familial breast cancer cases, who underwent genetic testing between 2009-2011 at the Institute of Oncology Ljubljana.

Informed written consent was obtained from all women enrolled in the study. The study protocol was approved by the National Medical Ethics Committee of the Republic of Slovenia (No. 61/06/07).

\section{Data collection}

Women enrolled in breast cancer case-control study were invited to participate through a postal questionnaire. Detailed questions were asked regarding sex hormone intake, with an emphasis on HRT use. A color chart displaying all preparations ever marketed in Slovenia was included in the questionnaire to aid recall. Information was obtained on the duration of HRT use (3 categories: less than 1 year, short-term use: $1<5$ years, long-term use: 5 or more years) and regimen of HRT use (estrogen therapy, estrogen plus progestin therapy - there was no tibolone or other non-estrogen user). Users of systemic and/or local route of HRT administration were included in the analyses. HRT use for less than 1 year was considered no use. Women were considered postmenopausal if they had selfreported their last menstrual bleeding being at least 12 months before the reference date or had undergone a bilateral oophorectomy.

Information on tumor characteristics in sporadic breast cancer cases was retrieved from pathology reports in the patient's medical records. Tumor grading was performed according to the Nottingham scheme [13]. This grading method evaluates three parameters and assigns a score of 1 to 3 for each parameter: tubule formation ( $>75 \%=1,10 \%$ to $75 \%=2,<10 \%=3$ ), nuclear atypia (none $=1$, moderate $=2$, marked $=3$ ), and number of mitoses per 10 high-power fields (HPF), based on a HPF size of $0.274 \mathrm{~mm}^{2}$ (< 10 mitoses $=1,10$ to 19 mitoses $=2$, $\geq 20$ mitoses $=3$ ). The final Nottingham histologic grade is based on the sum of scores of the three parameters: 3,4 or $5=$ grade 1,6 or $7=$ grade 2 , 8 or 9 = grade 3 ). Hormone receptor (HR) status (estrogen receptor (ER), progesterone receptor (PR)) was ascertained using immunohistochemical (IHC) testing, tumors with $\geq 10 \%$ nuclear staining were considered positive for the respective antibody. HER2 protein expression was determined by IHC using HercepTest ${ }^{\mathrm{TM}}$ (DAKO corp., CA, USA). HER2 gene amplification was determined by dual-color fluorescent in situ hybridization (FISH) using PathVysion ${ }^{\circledR}$ HER2 DNA probe kit and Paraffin pretreatment kit (both Abbot-Vysis, Inc., Downers Grove, IL, USA). HER2 was considered positive when scored $3+$ on the IHC staining and/or the 
ratio of HER2 signal to chromosome 17 signal in 60 cells by FISH analysis scored $>2.2$.

\section{Genotyping}

In sporadic breast cancer case patients, DNA was extracted from archived paraffin-embedded non-malignant breast tissues using HP PCR Template Preparation Kit (Roche Diagnostics GmbH, Mannheim, Germany). In familial breast cancer cases and controls, genomic DNA was extracted from whole blood using the FlexiGene DNA Kit 250 (Qiagen GmbH, Hilden, Germany).

Genotyping for the KRAS variant was carried out using the 5' nuclease assay (TaqMan; Applied Biosystems, Werterstadt, Germany). The reaction employed TaqMan Genotyping PCR Master Mix, forward primer 5-GCCAGGCTGGTCTCGAA-3, reverse primer 5CTGAATAAATGAGTTCTGCAAAACAGGTT-3, probe-1 VIC-CTCAAGTGATTCACCCAC-MGB and probe 2 FAM-CAAGTGATGCACCCAC-MGB, as previously described [7]. Analysis was performed using the ABI PRISM ${ }^{\circledR} 7900$ HT Sequence Detection System and SDS 2.4 software (Applied Biosystems, Werterstadt, Germany). Some of the samples (0.7\%) failed to be genotyped due to poor DNA quality. Assay reliability was assessed by random selection of $5 \%$ of samples in which genotypes were confirmed by sequencing using the 3500 Genetic Analyzer (Applied Biosystems, Werterstadt, Germany). Concordance rate was $100 \%$.

\section{Statistical analysis}

Descriptive and summary statistics were used to describe patient and breast tumor characteristics in the dataset. Observed genotype frequencies were tested for deviation from Hardy-Weinberg equilibrium with the chi-square goodness-of-fit test. The homozygous wildtype genotype, as determined by the more common of the homozygous genotypes, served as a reference category, with the heterozygous genotype and homozygous variant genotypes being collapsed into one category. Associations between the KRAS genotype and breast tumor characteristics in relation to HRT use were assessed using chi-square test. Odds ratios (ORs) for breast cancer risk and the corresponding 95\% confidence intervals (CI) were calculated using logistic regression analysis. All reported $\mathrm{p}$ values are two-sided and considered statistically significant if $p<0.05$. Analyses were performed using SPSS 19.0 software package (SPSS, Chicago, IL, USA).

\section{Results}

The study population consisted of 530 postmenopausal sporadic breast cancer cases, 165 familial breast cancer cases (including $\mathrm{N}=20$, who test positive for $B R C A 1$ mutations and $\mathrm{N}=9$, who test positive for $B R C A 2$ mutations) and 270 postmenopausal control women with no history of breast and/or ovarian cancer. The mean age for sporadic breast cancer cases, familial breast cancer cases and controls was $60.45 \pm 5.84,39.75$ \pm 11.52 and $60.10 \pm 5.85$ years, respectively.

Genotype frequencies were close to those expected under Hardy-Weinberg equilibrium in both cases and controls ( $p>0.05)$. No evidence of association was observed between the KRAS variant and risk of sporadic and familial breast cancer - either among $B R C A$ carriers or non-BRCA carriers. The KRAS variant allele was detected in $17.2 \%$ of sporadic breast cancer cases and in $18.2 \%$ of all familial cases $(10.3 \%$ of $B R C A$ carriers $10.0 \%$ of $B R C A 1$ and $11.1 \%$ of $B R C A 2$ carriers and in $19.9 \%$ of non- $B R C A$ carriers). These frequencies were not statistically significantly different from the prevalence of the variant allele in controls (17.8\%, Table 1).

We further evaluated whether the KRAS variant associates with a particular breast tumor characteristic. Analyses were carried out for all sporadic breast cancer cases, sporadic breast cancer cases using HRT ( $\geq 1$ year of HRT use) and sporadic breast cancer cases not using HRT $(0<1$ years of HRT use).

Table 1 KRAS genotype frequencies in the study population

\begin{tabular}{|c|c|c|c|c|}
\hline $\begin{array}{l}\text { Study } \\
\text { population }\end{array}$ & Genotype & $\begin{array}{l}\text { Frequency } \\
\mathrm{N} \%\end{array}$ & OR $(95 \% \mathrm{Cl})$ & $\begin{array}{l}\mathrm{p} \\
\text { value }\end{array}$ \\
\hline \multirow[t]{2}{*}{ Controls } & wild (TT) & $\begin{array}{l}221 / 269 \\
(82.2)\end{array}$ & 1.0 & \\
\hline & $\begin{array}{l}\text { variable (TG/ } \\
\text { GG) }\end{array}$ & $\begin{array}{l}48 / 269 \\
(17.8) \\
\end{array}$ & & \\
\hline \multirow[t]{2}{*}{ Sporadic cases } & wild (TT) & $\begin{array}{l}434 / 524 \\
(82.8)\end{array}$ & $\begin{array}{l}0.96(0.65- \\
1.40)\end{array}$ & 0.814 \\
\hline & $\begin{array}{l}\text { variable (TG/ } \\
\text { GG) }\end{array}$ & $\begin{array}{l}90 / 524 \\
(17.2)\end{array}$ & & \\
\hline \multirow[t]{2}{*}{ Familial cases } & wild (TT) & $\begin{array}{l}135 / 165 \\
(81.8)\end{array}$ & $\begin{array}{l}1.02(0.62- \\
1.69)\end{array}$ & 0.929 \\
\hline & $\begin{array}{l}\text { variable (TG/ } \\
\text { GG) }\end{array}$ & $\begin{array}{l}30 / 165 \\
(18.2)\end{array}$ & & \\
\hline \multirow[t]{2}{*}{ BRCA carriers } & wild (TT) & $26 / 29(89.7)$ & $\begin{array}{l}0.53(0.15- \\
1.83)\end{array}$ & 0.316 \\
\hline & $\begin{array}{l}\text { variable (TG/ } \\
\text { GG) }\end{array}$ & $3 / 29(10.3)$ & & \\
\hline \multirow[t]{2}{*}{ BRCA1 carriers } & wild (TT) & $18 / 20(90.0)$ & $\begin{array}{l}0.51(0.12- \\
2.28)\end{array}$ & 0.379 \\
\hline & $\begin{array}{l}\text { variable (TG/ } \\
\text { GG) }\end{array}$ & $2 / 20(10.0)$ & & \\
\hline \multirow[t]{2}{*}{ BRCA2 carriers } & wild (TT) & $8 / 9(88.9)$ & $\begin{array}{l}0.58(0.07- \\
4.71)\end{array}$ & 0.606 \\
\hline & $\begin{array}{l}\text { variable (TG/ } \\
\mathrm{GG} \text { ) }\end{array}$ & $1 / 9(11.1)$ & & \\
\hline \multirow[t]{2}{*}{$\begin{array}{l}\text { Non-BRCA } \\
\text { carriers }\end{array}$} & wild (TT) & $\begin{array}{l}109 / 136 \\
(80.1)\end{array}$ & $\begin{array}{l}1.14(0.68- \\
1.93)\end{array}$ & 0.623 \\
\hline & $\begin{array}{l}\text { variable (TG/ } \\
\text { GG) }\end{array}$ & $\begin{array}{l}27 / 136 \\
(19.9)\end{array}$ & & \\
\hline
\end{tabular}


Approximately one third of the sporadic breast cancer cases ( $\mathrm{n}=157,29.6 \%$ ) were using HRT prior to diagnosis, $14.3 \%$ for short-term $(1<5$ years of HRT use) and $15.3 \%$ for long-term ( $\geq 5$ years of HRT use). Among HRT users, more than two thirds ( $\mathrm{n}=131,71.2 \%$ ) were using combined estrogen plus progestin HRT (Table 2).

The vast majority of patients $(n=444,84.9 \%)$ had invasive ductal carcinoma, followed by invasive lobular carcinoma ( $\mathrm{n}=62,11.9 \%)$ and other special types of carcinoma ( $n=17,3.2 \%$ ) of which there were mucinous, tubular, cribriform and medullary carcinomas. Distributions of other breast tumor characteristics are presented in Table 3.

The prevalence of the KRAS variant was evenly distributed between $\mathrm{HR}^{+}$and $\mathrm{HR}^{-}$tumors (Table 4). The $K R A S$ variant was statistically significantly more often associated with HER2 ${ }^{+}(42.9 \%)$ than HER2- $(13.3 \%)$ tumors and with tumors of higher histopathologic grade - score $3(28.6 \%)$ vs. score 1 and 2 (9.6\%). However, both associations were detected only in HRT users (Tables 4 and 5).

To determine which of the three parameters (tubular formation, nuclear atypia, mitotic index) contributed to the higher histopathologic grade among HRT users carrying the variant allele, we evaluated the association of the KRAS variant with the particular parameter of the histopathologic grade among HRT users. KRAS variant was statistically significantly more often associated with tumors of marked nuclear atypia - score 3 (24.2\%) vs. score 1 and 2 (8.9\%) and with tumors of higher mitotic index - score 3 (28.9\%) vs. score 1 and 2 (9.7\%) (Table $6)$. On the other hand, the prevalence of the KRAS variant was not statistically significantly different in regards to what percent of the tumor formed normal duct structures (Table 6).

No statistically significant difference among KRAS variant carriers and non-carriers was noted in the distribution of histologic type of the tumor, tumor size, vascular invasion and lymph node involvement (data not shown).

\section{Discussion}

The present study provides no evidence of association between the KRAS variant and risk of sporadic and of familial breast cancer - either among $B R C A$ mutation carriers or non-BRCA mutation carriers.

The lack of association between the KRAS variant and sporadic postmenopausal breast cancer is in line with the previous findings reported by Paranjape and colleagues [11]. Although the $K R A S$ variant was significantly associated with triple negative breast cancer in premenopausal women, this association was not observed for postmenopausal women regardless of HR and HER2 status [11].

In contrast to Hollestelle and colleagues [10], who found increased frequency of the KRAS variant among cases from $B R C A 1$ positive families, we did not observe an association between the KRAS variant and either cases from $B R C A 1, B R C A 2$ or non-BRCA breast cancer families. The reason for this discrepancy might be insufficient power due to our medium-sized familial breast cancer population, however, relatively narrow confidence intervals suggest that the effect of a larger sample would not be substantial. Furthermore, expansion of the number of $B R C A 1$ mutation carriers by including other family members in addition to the index cases in the study by Hollestelle and colleagues did also not improve significance, nor did the $K R A S$ variant appear to modify breast cancer risk for $B R C A 1$ mutation carriers [10]. Since $B R C A 1$ mutations have been consistently associated with increased risk of triple negative breast cancer, Paranjape and colleagues evaluated whether the observed association of the KRAS variant with premenopausal triple negative breast cancer was only due to its association with carriers of $B R C A 1$ mutation. They found no association between the KRAS variant and $B R C A 1$ mutations, however, the $K R A S$ variant was associated with a $B R C A 1$ mutation-like gene expression signature [11]. This implies that there might be an increased oncogenic risk in the presence of the KRAS variant, but other mechanisms that uniquely down-

Table 2 Distribution of HRT use among sporadic breast cancer cases

\begin{tabular}{lll}
\hline Patients characteristics & Sporadic breast cancer cases $\mathbf{N}(\%)$ \\
\hline HRT use & Nonusers: $0<1$ years & $373(70.4)$ \\
& Short-term users: $1<5$ years & $76(14.3)$ \\
& Long-term users: $\geq 5$ years & $81(15.3)$ \\
& Missing & 0 \\
Regimen of HRT* & Estrogen only & $53(28.8)$ \\
& Estrogen plus progestin & $131(71.2)$ \\
\hline
\end{tabular}

\footnotetext{
* Among those who ever used HRT
} 
Table 3 Distribution of breast tumor characteristics among sporadic breast cancer cases

\begin{tabular}{|c|c|c|}
\hline $\begin{array}{l}\text { Tumor } \\
\text { characteristics }\end{array}$ & & $\begin{array}{l}\text { Sporadic breast cancer cases } \\
\mathrm{N}(\%)\end{array}$ \\
\hline \multicolumn{3}{|l|}{ Histologic type } \\
\hline & Ductal & $444(84.9)$ \\
\hline & Lobular & $62(11.9)$ \\
\hline & Special-type & $17(3.2)$ \\
\hline & Missing & 7 \\
\hline \multicolumn{3}{|l|}{ Tumor size } \\
\hline & $\leq 20 \mathrm{~mm}$ & $349(67.2)$ \\
\hline & $21-50 \mathrm{~mm}$ & $152(29.3)$ \\
\hline & $>50 \mathrm{~mm}$ & $18(3.5)$ \\
\hline & Missing & 11 \\
\hline \multicolumn{3}{|c|}{ Histopathologic grade } \\
\hline & 1 & $89(17.1)$ \\
\hline & 2 & $227(43.6)$ \\
\hline & 3 & $205(39.3)$ \\
\hline & Missing & 9 \\
\hline \multicolumn{3}{|c|}{ Tubular formation } \\
\hline & 1 & $33(6.3)$ \\
\hline & 2 & $143(27.5)$ \\
\hline & 3 & $344(66.2)$ \\
\hline & Missing & 10 \\
\hline \multicolumn{3}{|l|}{ Nuclear atypia } \\
\hline & 1 & $16(3.1)$ \\
\hline & 2 & $267(51.3)$ \\
\hline & 3 & $237(45.6)$ \\
\hline & Missing & 10 \\
\hline \multicolumn{3}{|l|}{ Mitotic index } \\
\hline & 1 & 219(42.3) \\
\hline & 2 & $141(27.2)$ \\
\hline & 3 & $158(30.5)$ \\
\hline & Missing & 12 \\
\hline \multicolumn{3}{|c|}{ Vascular invasion } \\
\hline & No & $403(79.3)$ \\
\hline & Yes & $105(20.7)$ \\
\hline & Missing & 22 \\
\hline \multicolumn{3}{|l|}{$\begin{array}{l}\text { Lymph node } \\
\text { involvement }\end{array}$} \\
\hline & No & $288(57.5)$ \\
\hline & Yes & $213(42.5)$ \\
\hline & Missing & 29 \\
\hline \multicolumn{3}{|l|}{ HR status } \\
\hline & ER-PR- & 83(15.7) \\
\hline & $\begin{array}{l}E R+\text { and/or } \\
P R+\end{array}$ & $444(84.3)$ \\
\hline & Missing & 3 \\
\hline \multicolumn{3}{|l|}{ HER2 status } \\
\hline & HER2- & $449(87.7)$ \\
\hline & HER2+ & $63(12.3)$ \\
\hline & Missing & 18 \\
\hline
\end{tabular}

regulate BRCA1 activity are assumed to be involved $[11,14]$. Both studies $[10,11]$, including our own, are based on small-sized $B R C A 1$ positive populations, therefore, validation in a larger cohort of $B R C A 1$ mutation carriers is warranted.

Since the association of the KRAS variant with triple negative breast cancer risk reported by Paranjape and colleagues was noted only for premenopausal women, we carried out further analyses investigating the association between the KRAS variant and breast tumor characteristics in sporadic postmenopausal breast cancer cases stratified by HRT use. This article shows for the first time that the KRAS variant is more often associated with HER2 ${ }^{+}$tumors and tumors of higher histopathologic grade - the KRAS variant was enriched in tumors of marked nuclear atypia and of higher mitotic index. Intriguingly, aforementioned associations were detected only in HRT users. These findings support the notion that there might be a meaningful interaction between the $K R A S$ variant and hormonal exposure.

We previously showed that tumors arising in women taking HRT have a more favorable prognostic profile. Tumors in HRT users were significantly smaller with lower grade and lower mitotic index compared to tumors in nonusers [15]. The present analysis, on the other hand, revealed that HRT use in women carrying the KRAS variant allele is associated with HER2 overexpressed and poorly-differentiated breast tumors, both indicators of a worse prognosis. The plausable mechanism for this switch caused by the KRAS genotype might be the cross-talk between steroid hormone-, growth factor- and let-7 miRNA-directed pathways. It has been postulated that aberrations in growth factor pathways could dramatically influence steroid hormone action [16]. The KRAS oncogene is an early player in many growth factor signal transduction pathways and its overexpression can lead to increased activation of the RAF/ $\mathrm{MEK} /$ mitogen activated protein kinase (MAPK) pathway, which in turn phosphorylate and thereby activate ER $\alpha$ [17]. Although there was not a substantial change in KRAS mRNA, Paranjape and colleagues reported an enrichment of both NRAS mutant and MAPK activation signatures in breast tumors that had the KRAS variant [11]. Another explanation could involve reduced expression of let-7 miRNA family members in KRAS variantassociated breast tumors [6,11]. Indeed, recently identified compelling evidence demonstrated that let-7 miRNAs target ER $\alpha$ and thereby repress estrogen signaling by causing a halt in cell proliferation and apoptosis [18]. Taken together, these observations suggest that due to the KRAS variant-driven up-regulation of growth factordirected pathways and down-regulation of let-7 
Table 4 KRAS genotype frequencies and HR status and HER2 status according to HRT stratification

\begin{tabular}{|c|c|c|c|c|c|c|c|}
\hline \multirow[t]{2}{*}{ Study population } & \multirow[t]{2}{*}{ Genotype } & \multicolumn{2}{|c|}{$\begin{array}{c}\text { Frequency } \\
\mathrm{N}(\%)\end{array}$} & \multirow[t]{2}{*}{$\begin{array}{c}p \\
\text { value }\end{array}$} & \multicolumn{2}{|c|}{$\begin{array}{c}\text { Frequency } p \\
N(\%)\end{array}$} & \multirow[t]{2}{*}{$\begin{array}{c}\mathrm{p} \\
\text { value }\end{array}$} \\
\hline & & $\mathrm{HR}^{+}$ & $\mathrm{HR}^{-}$ & & HER2 $^{+}$ & HER2 $^{-}$ & \\
\hline \multirow[t]{2}{*}{ All } & wild(TT) & $363(82.9)$ & $69(83.1)$ & 0.955 & $49(77.8)$ & $372(84.0)$ & 0.218 \\
\hline & variable(TG/GG) & $75(17.1)$ & $14(16.9)$ & & $14(22.2)$ & $71(16.0)$ & \\
\hline Nonusers: HRT < 1 year & wild(TT) variable(TG/GG) & $250(81.7) 56(18.3)$ & $52(85.2) 9(14.8)$ & 0.508 & $41(83.7) 8(16.3)$ & $255(82.8) 53(17.2)$ & 0.879 \\
\hline \multirow[t]{2}{*}{ Users: HRT 1 years } & wild(TT) & $113(85.6)$ & $17(77.3)$ & 0.318 & $8(57.1)$ & $117(86.7)$ & 0.004 \\
\hline & variable(TG/GG) & $19(14.4)$ & $5(22.7)$ & & $6(42.9)$ & $18(13.3)$ & \\
\hline
\end{tabular}

Statistically significant results are shown in bold

Table 5 KRAS genotype frequencies and histopathologic grade according to HRT stratification

\begin{tabular}{|c|c|c|c|c|}
\hline \multirow[t]{3}{*}{ Study population } & \multirow[t]{3}{*}{ Genotype } & \multirow{2}{*}{\multicolumn{2}{|c|}{$\begin{array}{c}\text { Frequency } \\
\mathrm{N}(\%)\end{array}$}} & \multirow[t]{3}{*}{$\mathrm{p}$ value } \\
\hline & & & & \\
\hline & & $1 / 2$ & 3 & \\
\hline \multirow[t]{2}{*}{ All } & wild(TT) & $261(84.2)$ & $165(80.5)$ & 0.276 \\
\hline & variable(TG/GG) & $49(15.8)$ & $40(19.5)$ & \\
\hline \multirow[t]{2}{*}{ Nonusers: HRT < 1 year } & $\operatorname{wild}(T T)$ & $167(81.1)$ & $130(83.3)$ & 0.578 \\
\hline & variable(TG/GG) & 39(18.9) & $26(16.7)$ & \\
\hline \multirow[t]{2}{*}{ Users: HRT 1 years } & wild(TT) & $94(90.4)$ & $35(71.4)$ & 0.003 \\
\hline & variable(TG/GG) & 10(9.6) & $14(28.6)$ & \\
\hline
\end{tabular}

Statistically significant results are shown in bold

Table 6 KRAS genotype frequencies and histopathologic grade components among HRT users

\begin{tabular}{|c|c|c|c|c|}
\hline \multirow[t]{2}{*}{ Histopathologic grade components } & \multirow[t]{2}{*}{ Genotype } & \multicolumn{2}{|c|}{$\begin{array}{c}\text { Frequency } \\
\mathrm{N}(\%)\end{array}$} & \multirow[t]{2}{*}{$p$ value } \\
\hline & & $1 / 2$ & 3 & \\
\hline \multirow[t]{2}{*}{ Tubular formation } & wild(TT) & $54(87.1)$ & 75(83.3) & 0.525 \\
\hline & variable(TG/GG) & $8(12.9)$ & 15(16.7) & \\
\hline \multirow[t]{2}{*}{ Nuclearatypia } & wild(TT) & $82(91.1)$ & $47(75.8)$ & 0.010 \\
\hline & variable(TG/GG) & $8(8.9)$ & $15(24.2)$ & \\
\hline \multirow[t]{2}{*}{ Mitoticindex } & wild(TT) & $102(90.3)$ & $27(71.1)$ & 0.004 \\
\hline & variable(TG/GG) & $11(9.7)$ & $11(28.9)$ & \\
\hline
\end{tabular}

Statistically significant results are shown in bold

miRNAs, ER $\alpha$ and its downstream events might be upregulated. Therefore, it is conceivable that ER $\alpha$ mediated cellular growth might be even more prominent in the case of additional exogenous estrogen intake. This was confirmed by our results showing the KRAS variant to be more often associated with tumors of marked nuclear atypia and of higher mitotic index in HRT users. An independent validation in another cohort is still required before any firm conclusions can be drawn.

\section{Conclusion}

Given the increasing literature on a critical role of the $K R A S$ variant in human cancers, more studies are needed to unravel the functional role of the KRAS variant and delineate the exact mechanism of the putative cross-talk between the KRAS variant and steroid hormone exposure. Modification of the effect of HRT use on breast cancer risk by the KRAS variant shown in our study is highly reasonable. Further insight into this is important, as it may eventually result in the ability to identify postmenopausal women who are particularly susceptible to breast cancer when exposed to surplus exogenous hormones for longer periods.

\section{Abbreviations}

Cl: Confidence interval; EOC: Epithelial ovarian cancer; E: Estrogen; ER: Estrogen receptor; ERE: Estrogen response element; FISH: Fluorescent in situ hybridization; HBOC: Hereditary breast and ovarian cancer; HER2: Human epidermal growth factor receptor 2; HPF: High-power fields; HR: Hormone receptor; HRT: Hormone replacement therapy; IHC: Immunohistochemistry; MAPK: Mitogen activated protein kinase; NSCLC: Non-small-cell lung cancer; 
OR: Odds ratio; PR: Progesterone receptor; SNP: Single nucleotide polymorphism.

\section{Acknowledgements}

We would like to thank Snjezana Frkovic-Grazio, MD for her help with providing and interpreting pathology data. This work was supported by grant L3-0431 from the Slovenian Research Agency.

\section{Author details}

'Institute of Medical Genetics, Department of Obstetrics and Gynecology, University Medical Center Ljubljana, Slajmerjeva 3, Ljubljana 1000, Slovenia. ${ }^{2}$ Department of Molecular Diagnostics, Institute of Oncology Ljubljana, Zaloska 2, Ljubljana 1000, Slovenia.

\section{Authors' contributions}

JZC, VS, KG and SN designed the investigation. JZC carried out the molecular genetic studies, analyzed the data, interpreted the results and drafted the manuscript. SN edited the manuscript. All authors read and approved the final manuscript.

\section{Competing interests}

The authors declare that they have no competing interests.

Received: 7 November 2011 Accepted: 22 March 2012

Published: 22 March 2012

\section{References}

1. Bartel DP: MicroRNAs: genomics, biogenesis, mechanism, and function. Cell 2004, 116:281-297.

2. Esquela-Kerscher A, Slack FJ: Oncomirs - microRNAs with a role in cancer. Nat Rev Cancer 2006, 6:259-269.

3. Kent OA, Mendell JT: A small piece in the cancer puzzle: microRNAs as tumor suppressors and oncogenes. Oncogene 2006, 25:6188-6196.

4. Johnson SM, Grosshans H, Shingara J, Byrom M, Jarvis R, Cheng A, et al: RAS is regulated by the let-7 microRNA family. Cell 2005, 120:635-647.

5. Chin L, Ratner E, Leng S, Zhai R, Nallur S, Babar I, et al: A SNP in a let-7 microRNA complementary site in the KRAS 3' UTR increases non-small cell cancer risk. Cancer Res 2008, 68:8535-8540.

6. Takamizawa J, Konishi H, Yanagisawa K, Tomida S, Osada H, Endoh H, et al: Reduced expression of the let-7 microRNAs in human lung cancers in association with shortened postoperative survival. Cancer Res 2004, 64:3753-3756.

7. Christensen BC, Moyer BJ, Avissar M, Ouellet LG, Plaza SL, McClean MD, et al: A let-7 microRNA-binding site polymorphism in the KRAS $3^{\prime}$ UTR is associated with reduced survival in oral cancers. Carcinogenesis 2009, 30:1003-1007.

8. Ratner E, Lu L, Boeke M, Barnett R, Nallur S, Chin LJ, et al: A KRAS-variant in ovarian cancer acts as a genetic marker of cancer risk. Cancer Res 2010, 70:6509-6515

9. Pharoah PDP, Palmieri RT, Ramus SJ, Gayther SA, Andrulis IL, AntonCulver $\mathrm{H}$, et al: The role of KRAS rs61764370 in invasive epithelial ovarian cancer: implications for clinical testing. Clin Cancer Res 2011, 17:3742-3750.

10. Hollestelle A, Pelletier C, Hooning M, Crepin E, Schutte M, Look M, et al: Prevalence of the variant allele rs61764370 T > G in the $3^{\prime}$ UTR of KRAS among Dutch $B R C A 1, B R C A 2$ and non-BRCA1/BRCA2 breast cancer families. Breast Cancer Res Treat 2011, 128:79-84

11. Paranjape T, Heneghan $H$, Lindner R, Keane FK, Hoffman A, Hollestelle A, et al: A 3'- untranslated region KRAS variant and triple-negative breast cancer: a case-control and genetic analysis. Lancet Oncol 2011, 12:377-386.

12. Cerne JZ, Gersak K, Novakovic S: The influence of the genetic variant within miRNA-binding site in estrogen receptor alpha gene on the risk of breast cancer in postmenopausal women on hormone replacement therapy. Cancer Biomark 2011, 8:123-128.

13. Elston CW, Ellis IO: Pathological prognostic factors in breast cancer. I. The value of histological grade in breast cancer: experience from a large study with long-term follow-up. Histopathology 1991, 19:403-410.

14. Kumar MS, Swanton C: KRAS 3'-UTR variants and stratification of breastcancer risk. Lancet Oncol 2011, 12:318-319.
15. Cerne JZ, Frkovic-Grazio S, Gersak K: Breast tumor characteristics in hormone replacement therapy users. Pathol Oncol Res 2011, 17:917-923.

16. Nicholson Rl, McClelland RA, Robertson JFR, Gee JMW: Involvement of steroid hormone and growth factor cross-talk in endocrine response in breast cancer. Endocr Relat Cancer 1999, 6:373-387.

17. Santen RJ, Song RX, McPherson R, Kumar R, Adam L, Jeng MH, et al: The role of mitogen-activated protein (MAP) kinase in breast cancer. J Steroid Biochem Mol Biol 2002, 80:239-256.

18. Zhao Y, Deng C, Wang J, Xiao J, Gatalica Z, Recker RR, et al: Let-7 family miRNAs regulate estrogen receptor alpha signaling in estrogen receptor positive breast cancer. Breast Cancer Res Treat 2011, 127:69-80.

\section{Pre-publication history}

The pre-publication history for this paper can be accessed here: http://www.biomedcentral.com/1471-2407/12/105/prepub

doi:10.1186/1471-2407-12-105

Cite this article as: Cerne et al: KRAS rs61764370 is associated with HER2-overexpressed and poorly-differentiated breast cancer in hormone replacement therapy users: a case control study. BMC Cancer 2012 12:105.

\section{Submit your next manuscript to BioMed Central and take full advantage of:}

- Convenient online submission

- Thorough peer review

- No space constraints or color figure charges

- Immediate publication on acceptance

- Inclusion in PubMed, CAS, Scopus and Google Scholar

- Research which is freely available for redistribution

Submit your manuscript at www.biomedcentral.com/submit
Ciomed Central 